\title{
Cytological and transcriptome analyses reveal OsPUB73 defect affects the gene expression associated with tapetum or pollen exine abnormality in rice
}

Lin Chen ${ }^{1,2,3,4,5}$, Ruilian Deng ${ }^{1,2,3}$, Guoqiang Liu ${ }^{1,2,3}$, Jing Jin ${ }^{2,3}$, Jinwen $\mathrm{Wu}^{1,2,3}$ and Xiangdong Liu $\mathrm{Lu}^{1,2,3^{*}}$ (D)

\begin{abstract}
Background: As one of the main crops in the world, sterility of rice (Oryza sativa L.) significantly affects the production and leads to yield decrease. Our previous research showed that OsPUB73, which encodes U-box domain-containing protein 73 , may be associated with male sterility. However, little information is available on this gene that is required for anther development. In the present study, we knocked out OsPUB73 by using the CRISPR/ Cas9 system and studied the cytological and transcriptome of the gene-defect associated with pollen development and sterility in the rice variety (Taichung 65).
\end{abstract}

Results: The sequence analysis indicated that OSPUB73 was comprised of 3 exons and 2 introns, of which CDS encoded 586 amino acids including a U-box domain. The expression pattern of OsPUB73 showed that it was highly expressed in the anther during meiosis stage. The ospub73 displayed low pollen fertility (19.45\%), which was significantly lower than wild type (WT) (85.37\%). Cytological observation showed tapetum vacuolated at the meiosis stage and pollen exine was abnormal at the bi-cellular pollen stage of ospub73. RNA-seq analysis detected 2240 down and 571 up-regulated genes in anther of ospub73 compared with WT during meiosis stage. Among of 2240 down-regulated genes, seven known genes were associated with tapetal cell death or pollen exine development, including CYP703A3 (Cytochrome P450 Hydroxylase703A3), CYP704B2 (Cytochrome P450 Hydroxylase704B2), DPW (Defective Pollen Wall), PTC1 (Persistant Tapetal Cell1), UDT1 (Undeveloped Tapetum1), OsAP37 (Aspartic protease37) and OSABCG15 (ATP binding cassette G15), which were validated by quantitative real-time polymerase chain reaction (qRT-PCR). These results suggested OsPUB73 may play an important role in tapetal or pollen exine development and resulted in pollen partial sterility.

Conclusion: Our results revealed that OsPUB73 plays an important role in rice male reproductive development, which provides valuable information about the molecular mechanisms of the U-box in rice male reproductive development.

Keywords: Rice, Ubiquitin ligase activity, Transcriptome, Male reproductive development

\footnotetext{
* Correspondence: xdliu@scau.edu.cn

${ }^{1}$ State Key Laboratory for Conservation and Utilization of Subtropical

Agro-Bioresources, South China Agricultural University, Guangzhou 510642,

China

${ }^{2}$ Guangdong Provincial Key Laboratory of Plant Molecular Breeding, South

China Agricultural University, Guangzhou 510642, China

Full list of author information is available at the end of the article
}

(c) The Author(s). 2019 Open Access This article is distributed under the terms of the Creative Commons Attribution 4.0 International License (http://creativecommons.org/licenses/by/4.0/), which permits unrestricted use, distribution, and reproduction in any medium, provided you give appropriate credit to the original author(s) and the source, provide a link to the Creative Commons license, and indicate if changes were made. The Creative Commons Public Domain Dedication waiver (http://creativecommons.org/publicdomain/zero/1.0/) applies to the data made available in this article, unless otherwise stated. 


\section{Background}

Rice (Oryza sativa L.) is one of the most essential agricultural crops and feeds over half of the global population. Improving the productivity of rice grain is necessary for food security. However, low seed setting is a major hindrance in the rice yields; moreover male reproductive development presents correlation with success in seed setting.

It is well known that male reproductive development is a critical biological process involving the generation of haploid pollen for sexual reproduction; and anther development is the principal event in male reproductive development [1,2]. The anther is comprised of a fourlobed structure, and each lobe includes microsporocytes, the epidermis, endothecium, middle layer, and tapetum after the morphogenesis. The tapetum is the innermost cell layer of the anther and provides a safe surrounding, necessary nutrients and enzymes during microspore development [3]. The tapetum begins to degenerate after the meiosis, which is considered to be a process of programmed cell death $(\mathrm{PCD})$. The tapetum degradation promotes the formation of pollen walls and releases microspores. Normal tapetum degradation is critical for the production of viable pollen grains in the male reproductive development, and abnormal tapetum degradation usually causes pollen sterility [4-6]. In the previous studies, some genes controlling tapetum development have been found in rice [7-14]. A MYB transcriptional factor (GAMYB) has been considered important for pollen development, and gamyb mutants displayed abnormal development of exine and Ubisch bodies [15, 16]. Li et al. [17] reported that PTC1 encodes a PHD-finger protein that controls tapetal degeneration, pollen wall formation, and aborted microspores.

The ubiquitin-proteasome system, which is involved in post-translational modification, is a key regulatory mechanism for plant growth and development $[18,19]$. The ubiquitin-proteasome system involves three essential enzymes, including ubiquitin-activating enzyme (E1), ubiquitin-conjugating enzyme (E2), and ubiquitin ligase (E3) [20]. The E3 ligase plays an important role in the regulation of the ubiquitin-proteasome system and confers specificity to the ubiquitination reaction. E3 ligases modify a large number of proteins or protein complexes, most of which contain RING, HECT, F-box, and U-box domains [21-24]. The U-box, which contains about 70 amino acids, is a highly conserved domain and the E3 ligase activity-related protein domain; and was first shown to be involved in polyubiquitin chain assembly in yeast $[25,26]$. A number of predicted plant U-box (PUB) family proteins in rice and Arabidopsis thaliana can be classified into nine groups according to their other distinguishing domains, including UFD2 specific motif+Ubox, U-box+ARM/HEAT, U-box+GKL-box, Kinase+U- box, U-box only, U-box+WD40, TPR + U-box, TPR + Kinase+U-box and MIF4G + U-box, and the Ubox+ARM/HEAT is the largest group [27]. PUB proteins are involved in various cellular processes in higher plants, including abiotic stress responses [28], plant hormone regulation [29,30], flowering time [31], cell division and elongation, plant cell death and defense responses [32, 33]. In addition, Atpub4 showed incomplete degeneration of tapetal cells and their pollen grains had abnormal exine structure. These results indicate that PUB family proteins also play an important role in the plant male fertility.

OsPUB73 encodes a U-box protein and possesses E3 ligase activity in rice [27]. Our previous research showed that OsPUB73 was down-regulated in autotetraploid rice hybrid of multi-allelic interactions at pollen sterility loci compared to corresponding diploid rice hybrid by transcriptome analysis, suggesting that OsPUB73 may be associated with male sterility in rice [34]. To investigate the molecular mechanism of OsPUB73, we developed ospub73 by using the CRISPR/Cas9 technology. Cytological observation was used to investigate the fertility of ospub73 and WT, and we primarily aimed to evaluate the role of OsPUB73 for male reproductive development. In addition, transcriptome analysis of anther was carried out to identify DEGs (differentially expressed genes) between ospub73 and WT during meiosis. Our study provides an important evidence of the role of PUB in regulating male reproductive development.

\section{Results}

Sequence analysis and expression pattern of OsPUB73

The sequence of OsPUB73 didn't show any variation in the Taichung-65 compared to Nipponbare by resequencing, and was consistent with the full-length sequence from the Rice Genome Annotation Project Database (http://rice.plantbiology.msu.edu/). The OsPUB73 comprised three exons and two introns (Fig. 1a). The CDS sequence of OsPUB73 is 1758 bp (Additional file 1: Figure S1), and it encodes ubiquitin ligase activityrelated protein of 586 amino acids, which includes a Ubox domain (Fig. 1b). Zeng et al. [27] found 77 and 63 genes encoding U-box domain-containing proteins in the rice and Arabidopsis genomes, respectively. The OsPUB73 belonged to V Class (U-box only). To investigate the phylogenetic relationship of $\mathrm{V}$ Class between rice and Arabidopsis, 12 genes (included $7 \mathrm{~V}$ Class in rice and $5 \mathrm{~V}$ Class in Arabidopsis) were used for sequence comparison and phylogenetic analysis. OsPUB73 and OsPUB26 were found to be an orthologous pair (Fig. 1c), and U-box domain was detected in all genes (Additional file 2: Figure S2).

The RT-PCR (rverse transcription polymerase chain reaction) and qRT-PCR analysis were used to survey the 


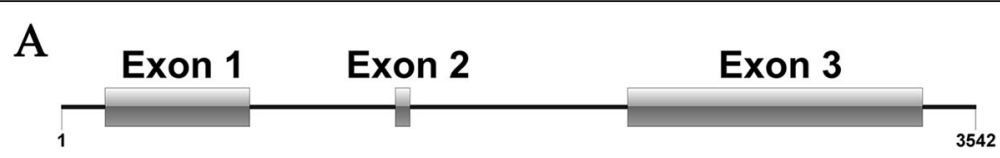

B

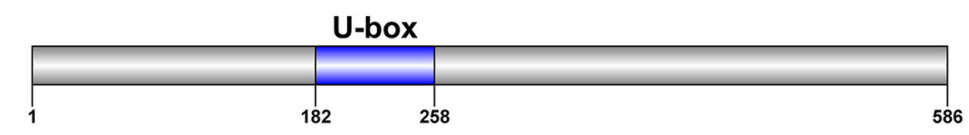

C

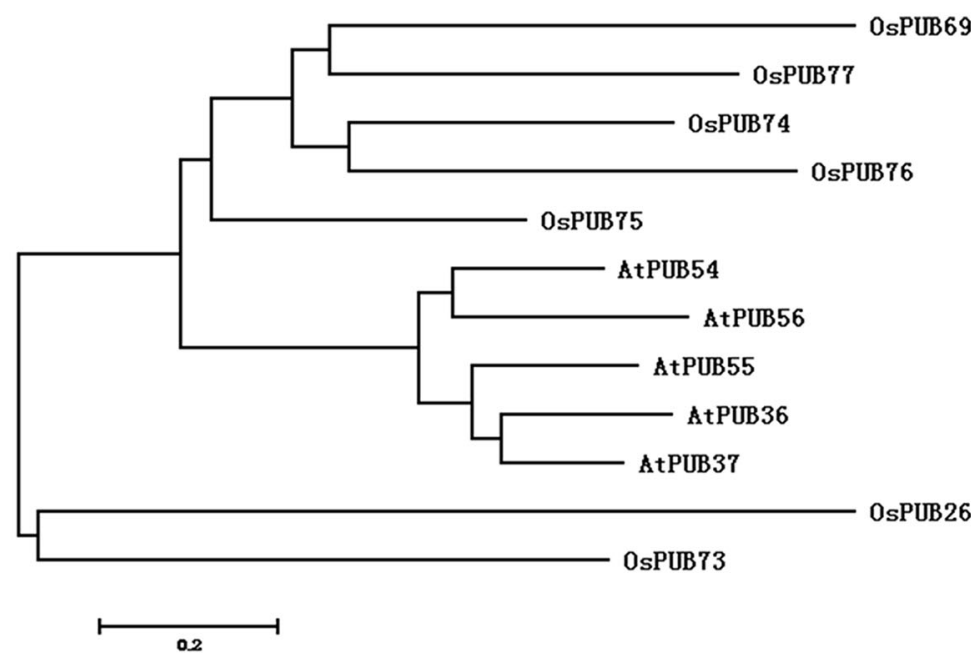

Fig. 1 The genome structure and phylogenetic analysis. a The genome structure of OsPUB73 in rice genome; $\mathbf{b}$ The site of U-box structure in OsPUB73; C, Comparative phylogenetic analysis of OSPUB73 protein in rice and arabidopsis, the evolution history was inferred using NeighborJoining phylogenetic tree generated with the MEGA6.0

spatial and temporal patterns of OsPUB73 in Taichung65 plants. The OsPUB73 expression was mainly identified in anthers during meiosis stage, and the expression of OsPUB73 was almost undetectable in the mature anthers. In addition, trace amounts of OsPUB73 expression were also detected in the roots, stems and leaves (Additional file 3: Figure S3). The high levels of OsPUB73 expression in meiosis stage anthers are consistent with its role in regulating male reproductive development.

\section{Creation of ospub73 using the CRISPR/Cas9 system}

To evaluate the function of OsPUB73, the CRISPR/Cas9 system was used to create ospub73 mutants. The CRISPR/Cas9 recombinant vector, which included three guide RNA targets in the first exon of OsPUB73, was used to transform the plant of Taichung-65. A total of $18 \mathrm{~T}_{0}$ transgenic plants were obtained and we analyzed the target site by sequencing PCR-amplified OsPUB73 genomic DNA from transgenic plants. There were six homozygous mutants, two bi-allelic mutants, seven heterozygous mutants, and three non-mutant plants in the transgenic plants (Additional file 4: Table S1). The ospub73-1 and ospub73-2 used to subsequent experiments (Fig. 2), and the $\mathrm{T}_{2}$ plants of ospub73-1 and ospub73-2 have been used for phenotyping and genetic analysis.

\section{Mutation of OsPUB73 cause pollen semi-sterility}

The ospub73 showed normal plant type as well as normal vegetative development (Additional file 5: Figure S4). However, the panicle of the ospub73 appeared many unfilled grains (Fig. 3a), and the seed setting of ospub73-1 and ospub73-2 were only 19.63 and $37.02 \%$, respectively, which were significantly lower than WT (85.37\%) (Fig. 3h). These results implied potential defects in pollen or embryo sac development. To verify our supposition, we investigated mature embryo sac (Fig. 3e-g) and pollen fertility (Fig. 3b-d) between mutant and WT. The mature embryo sac fertility of WT and ospub73 were nearly 90\% (Fig. 3j). However, many mature pollen grains were aborted in ospub73, and the pollen fertility of ospub73-1 and ospub73-2 were 16.85 and $22.05 \%$, respectively, which were significantly lower than the pollen fertility of WT (Fig. 3i). These phenomena indicated that there was no difference in embryo sac fertility between WT and ospub73, but that ospub73 displayed male 


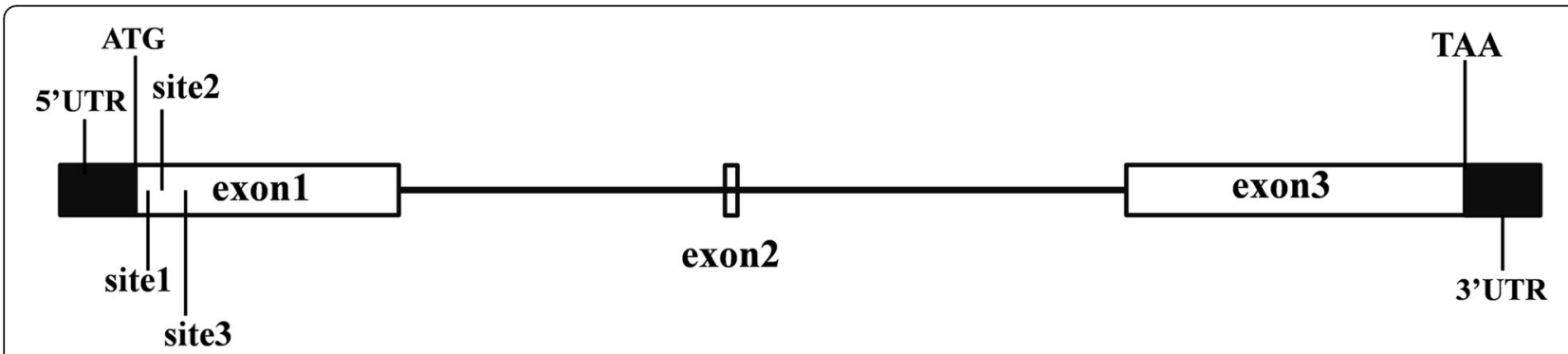

wT: AAGCGCAGCTTCGCCTCGA-GATGA AGGCAAAGAAGGCCAAGGCGGACATGTCTGGGT GCAACGCTCCAGCAGCCTCGACTTGGA

ospub73-1 Allele1: AAGCGCAGCTTCGCCTCG

CCTCGGCTTGGA (-58bp)

Allele2: AAGCGCAGCTTCGCCTCG

CCTCGGCTTGGA (-58bp)

ospub73-2 Allele1: AAGCGCAGCTTCGCCTCGAAGATGGAGTTGGCAAAGAAGGCC CCTCGGCTTGGA $(-34 \mathrm{bp})$ Allele2: AAGCGCAGCTTCGCCTCGAAGATGGAGTTGGCAAAGAAGGCC CCTCGGCTTGGA $(-34 \mathrm{bp})$

Fig. 2 Targeted mutagenesis in rice by the CRISPR/Cas9 system. The three target sites disrupt the first exon of ospub73. The black boxes show target sites
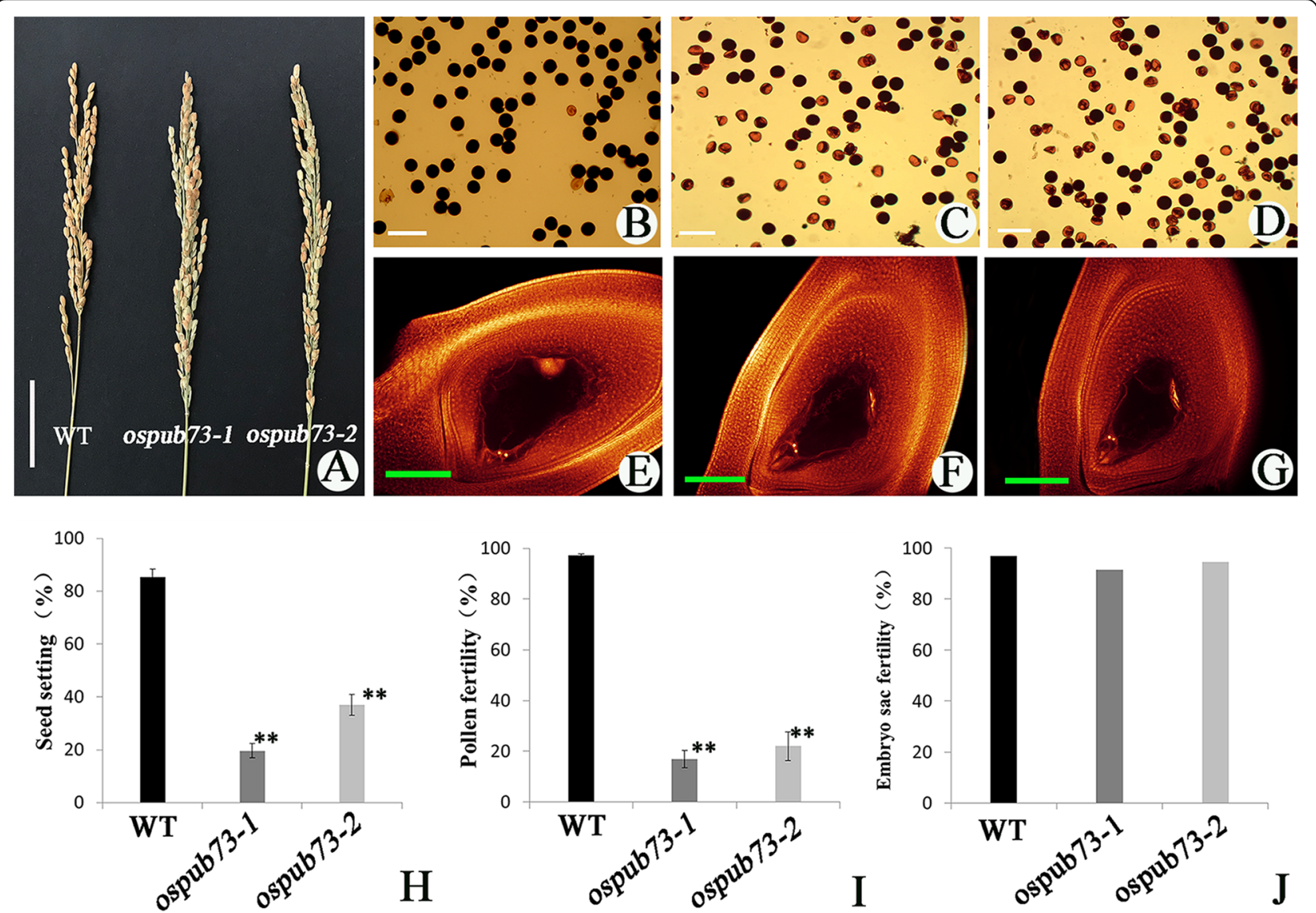

Fig. 3 Comparison of panicle, pollen fertility, and embryo sac fertility in WT and ospub73. a panicle, bar = $5 \mathrm{~cm}$; b-d pollen grains from WT (b), ospub73-1 (c) and ospub73-2 (d), bar = $100 \mu \mathrm{m}$; e-f embryo sac from WT (e), ospub73-1,(F) and ospub73-2 (g), bar = 100 $\mu$ m; $\mathbf{h}$ seed setting, sample size were $n=20$; i pollen fertility, sample size were $n=5$; j embryo sac fertility. ${ }^{* *}$ represent $p<0.01$. Error bars represent the SD 
semi-sterility. These results indicate that OsPUB73 may be involved in the pollen development.

\section{Analysis of chromosome behavior and anther development in ospub73 and WT}

To reveal the effects of OsPUB73, we compared chromosome behavior between ospub73 and WT at pollen mother cell meiosis using DAPI (4,6-diamidino-2-phenylindole) staining. Based on the previous classification of meiotic stages [35], meiosis stages could be divided into nine development stages, including prophase I (Fig. 4a and e), metaphase I (Fig. 4b and f), anaphase I (Fig. 4c and g), telophase I (Fig. 4d and h), metaphase II (Fig. $4 \mathrm{i}$ and $\mathrm{m}$ ), anaphase II (Fig. $4 \mathrm{j}$ and $\mathrm{n}$ ), telophase II (Fig. 4k and o) and tetrad (Fig. $4 \mathrm{l}$ and p). There were no differences in chromosome behavior between ospub73 and WT by our observation (Fig. 4).

The above results indicated that chromosome behavior of ospub73 is normal, which prompted us to further study ospub73 pollen tissues. The semi-thin section analysis was performed to investigate the pollen developmental process in ospub73 and WT. At the pre-meiosis stage, there was no obviously morphological difference between ospub73 and WT in the anther, and the epidermis, endothecium, middle layer, tapetum and microsporocyte were normal in both ospub73 and WT anthers (Fig. 5a and d). At meiosis stage, the pollen mother cells underwent normal meiosis and formed tetrads, and tapetum were vacuolated in ospub73 (Fig. 5b and e). At the tetrad stage, the pollen mother cells formed tetrads and the middle layer cells became very thin and degenerated. But in ospub73 anther, although the tetrads had formed, the tapetum seemed to be vacuolated (Fig. $5 \mathrm{c}$ and f). At the single microspore stage, the tapetum became more condensed and deeply stained (Fig. $5 g-h$ and $j-k$ ). At the mature pollen stage, the WT pollen grains were full of starch and the tapetum fully degenerated. However, ospub73 microspores were degenerated, whereas tapetum cells became more vacuolated and did not degenerate (Fig. 5i and l). In addition, the transmission electron microscopy (TEM) analysis showed the tapetum was condensed in WT (Fig. 6a and b), but the tapetum was vacuolated in ospub73 (Fig. 6d and e). This result was consistent with semi-thin section results. Moreover,

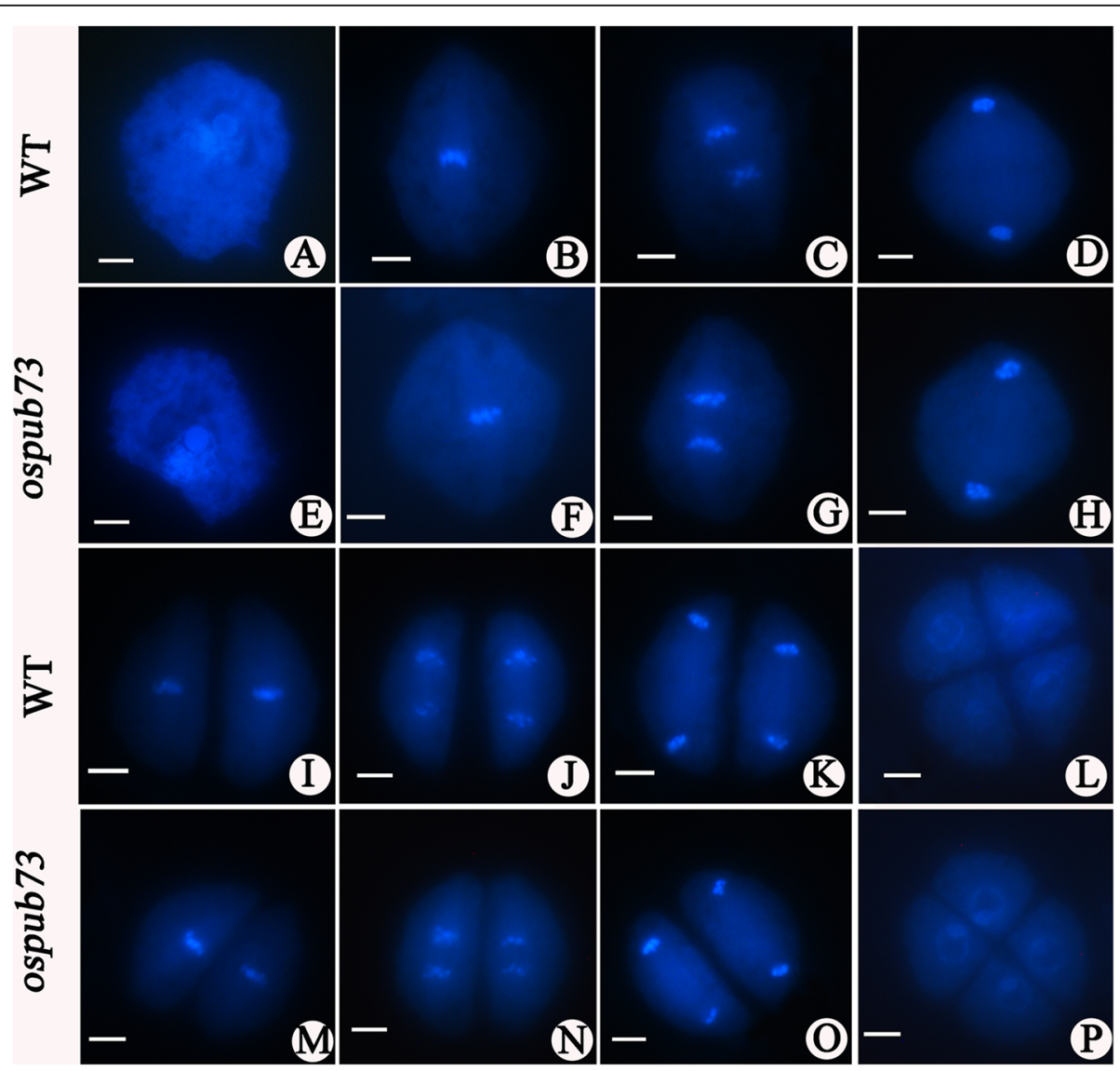

Fig. 4 Chromosome behavior of PMC meiosis in WT and ospub73 plant. a prophase I; $\mathbf{b}$ metaphase I; c anaphase I; $\mathbf{d}$ telophase I; e prophase II; $\mathbf{f}$ metaphase II; $\mathbf{g}$ anaphase $\|$; $\mathbf{h}$ telophase II; i tetrad stage. Bar $=50 \mu \mathrm{m}$ 


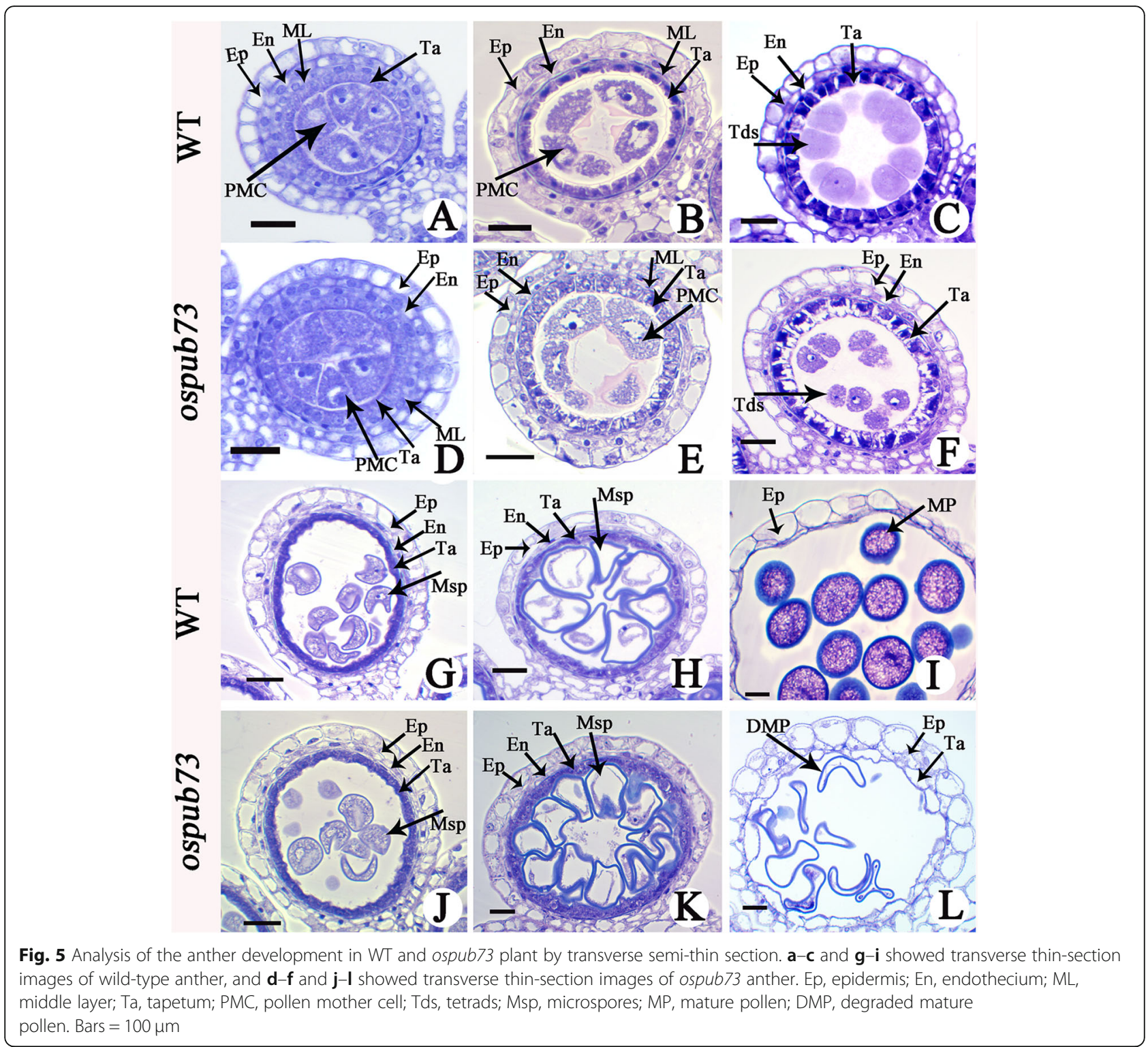

the pollen exine was abnormal at the bi-cellular pollen stage (Fig. 6f). These results suggest that ospub73 tapetum or pollen exine exhibit abnormality in rice.

\section{Homozygous ospub73 plants were identified for transcriptome analysis}

In order to study the gene regulatory network that is controlled by OsPUB73, we analyzed the transcriptome data generated from the anthers (meiosis stage) of homozygous ospub73-1 and WT control plants according to cytological results, which the mutant anther exhibited vacuolization during meiosis stage. The three biological replicates were established for each material. In total, about 19 million clean reads were detected in WT and ospub73 anthers during meiosis. The clean reads were aligned against the Nipponbare reference genome, and 92.91 to $93.61 \%$ annotated transcripts of the reference genome were obtained in ospub73 and WT rice, respectively (Table 1 ). The correlation coefficients were higher than 0.98 among the three biological replications (Additional file 6: Table S2), and principal component analysis (PCA) showed that replicate samples clustered together (Additional file 7: Figure S5). The correlation coefficients and PCA suggested that expression patterns have high similarity between biological replications.

Compared with WT anthers, a total of 2811 DEGs were found in ospub73, including 2240 down-regulated and 571 up-regulated genes (Additional file 8: Table S3). Gene ontology (GO) analysis showed that 85 and 4 GO were significantly enriched in the down and upregulated DEGs, respectively. In the biological processes 


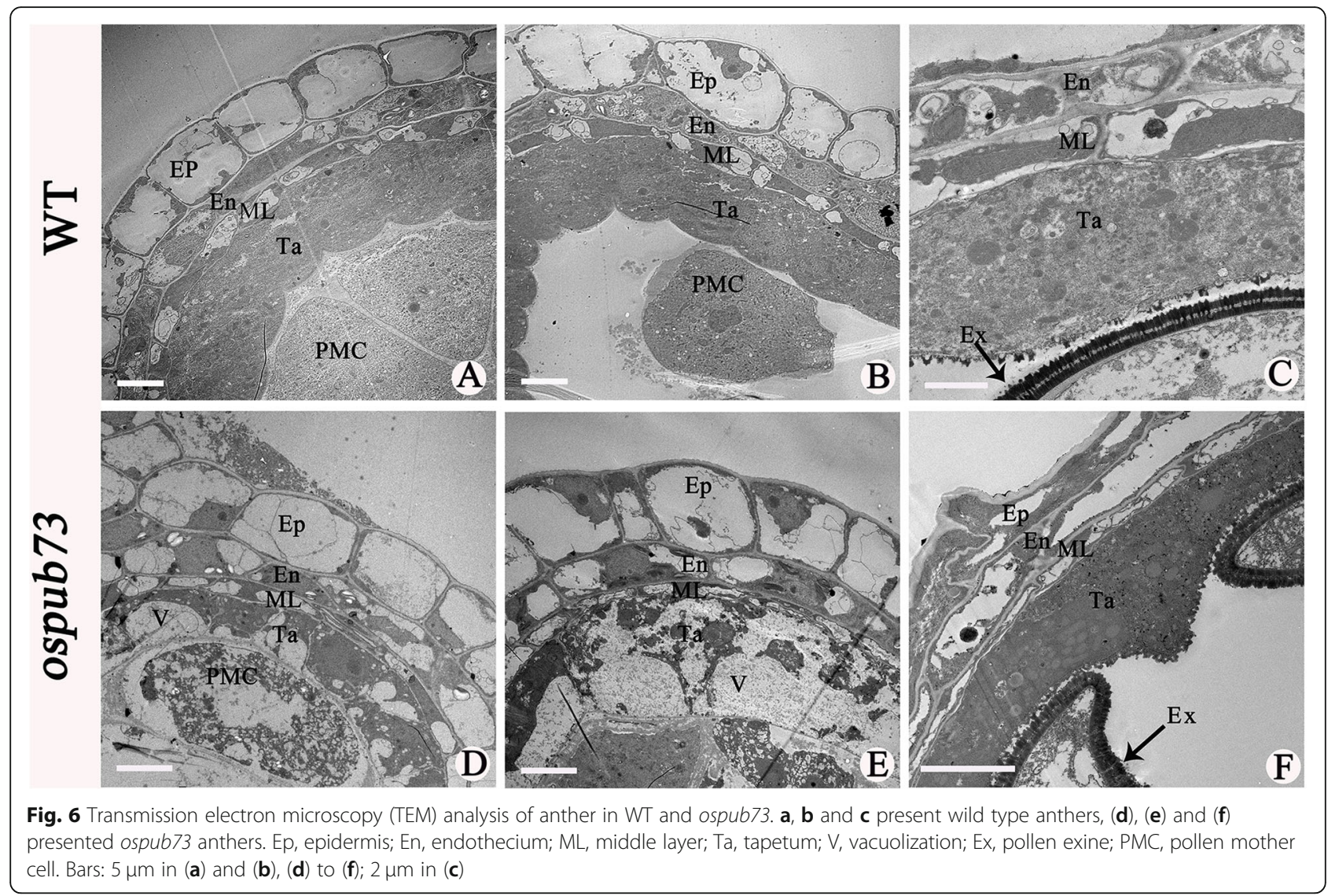

category, $41 \mathrm{GO}$ terms were significantly enriched in the down-regulated DEGs, such as regulation of the biosynthetic process, regulation of transcription, carbohydrate metabolic process, protein amino acid phosphorylation and protein modification process; and GO term of oxidation reduction was significantly enriched in the upregulated DEGs. In the molecular function category, 40 GO categories, such as oxidoreductase activity, protein kinase activity and kinase activity, were found to be enriched in the down-regulated DEGs while GO terms related to the oxidoreductase activity were detected in the up-regulated DEGs. In the cellular component category, a total of 4 and $2 \mathrm{GO}$ terms were identified to be significantly enriched in the down and up-regulated DEGs, respectively (Additional file 9: Table S4).
KEGG (Kyoto Encyclopedia of Genes and Genomes) analysis suggested that 109 pathways were identified in down-regulated DEGs. The top 20 most enriched pathways were Plant-pathogen interaction, Phenylpropanoid biosynthesis, Protein processing in endoplasmic reticulum, Plant hormone signal transduction, Starch and sucrose metabolism, Ubiquitin mediated proteolysis, Peroxisome in down-regulated DEGs (Fig. 7a). In total 52 pathways were identified in up-regulated DEGs. The top 20 most enriched pathways were mainly focused on the Photosynthesis, Carbon fixation in photosynthetic organisms, Plant hormone signal transduction, Glyoxylate and dicarboxylate metabolism, Endocytosis, Phenylpropanoid biosynthesis and DNA replication (Fig. 7b). The GO and KEGG analysis results showed that DEGs

Table 1 Overview of reads from WT and ospub73 anthers

\begin{tabular}{lllllll}
\hline Sample & Total Reads & Clean reads & Mapped Reads & Unique-Mapped Reads & GC Content & Q30 \\
\hline WT-1 & $66,973,324$ & $33,486,662$ & $62,602,452(93.47 \%)$ & $60,953,559(91.01 \%)$ & $54.80 \%$ & $93.72 \%$ \\
WT-2 & $67,440,172$ & $33,720,086$ & $62,884,344(93.24 \%)$ & $60,807,362(90.16 \%)$ & $54.95 \%$ & $93.83 \%$ \\
WT-3 & $61,328,580$ & $30,664,290$ & $57,182,779(93.24 \%)$ & $55,530,879(90.55 \%)$ & $54.78 \%$ & $93.53 \%$ \\
ospub73-1 & $65,360,720$ & $32,680,360$ & $60,727,192(92.91 \%)$ & $59,119,630(90.45 \%)$ & $54.45 \%$ & $93.58 \%$ \\
ospub73-2 & $60,833,960$ & $30,416,980$ & $56,557,714(92.97 \%)$ & $55,052,354(90.50 \%)$ & $54.27 \%$ & $93.52 \%$ \\
ospub73-3 & $58,140,984$ & $29,070,492$ & $54,423,148(93.61 \%)$ & $52,916,445(91.01 \%)$ & $53.99 \%$ & $93.56 \%$ \\
\hline
\end{tabular}



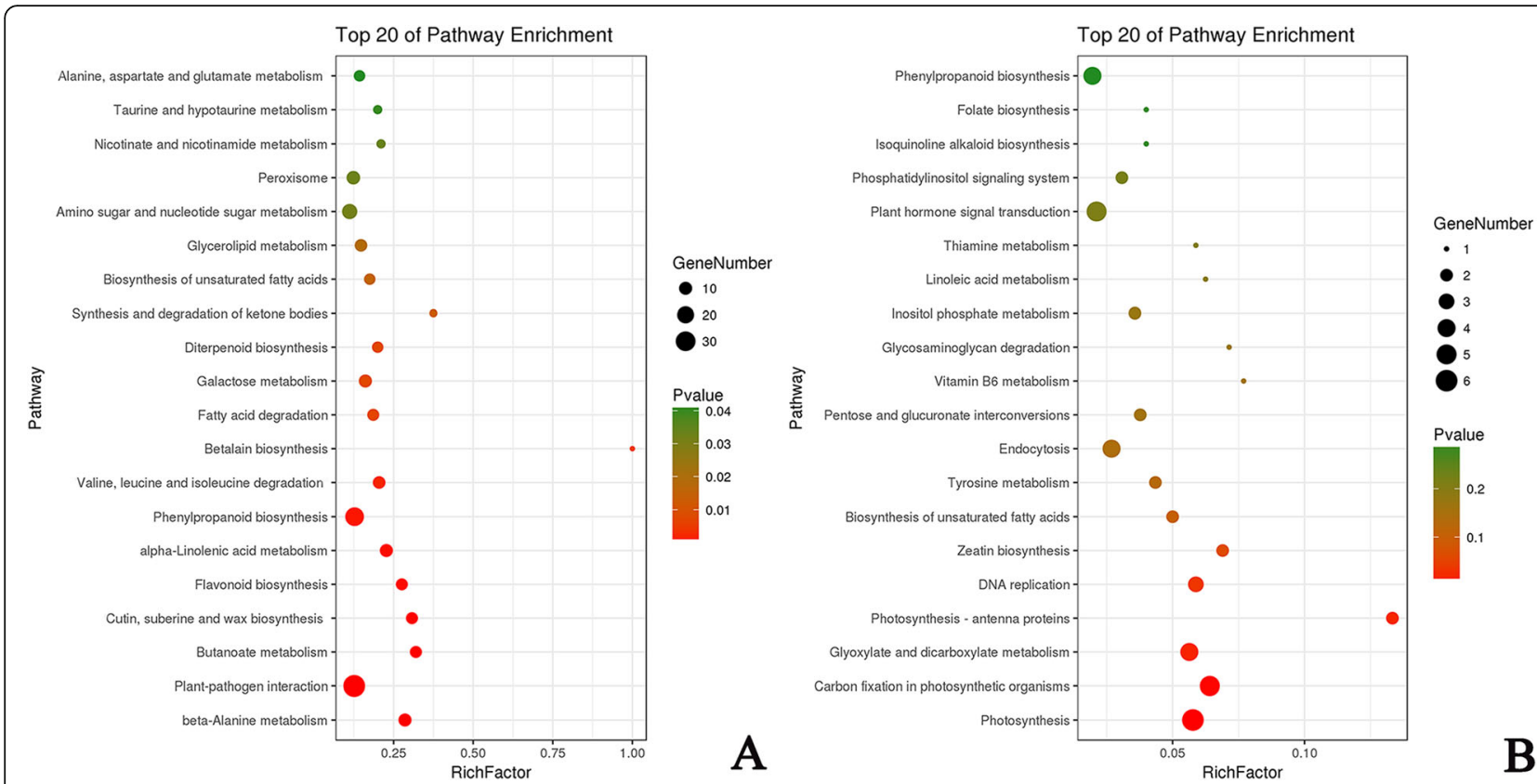

Fig. 7 KEGG pathway assignments of DEGs. a KEGG analysis of down-regulated DEGs. b KEGG analysis of up-regulated DEGs. Both (a) and (b) show the top 20 most represented categories and the number of transcripts predicted to belong to each category

involved in transcription, protein modification and signal transduction were more numerous in the downregulated DEGs.

In addition, we found that seven genes were associated with tapetum and pollen development, and these genes are down-regulated in ospub73, including CYP703A3, CYP704B2, DPW, PTC1, UDT1, OsAP37 and OsABCG15 (Additional file 8: Table S3). The gene expression were detected in anthers from different pollen stage by using qRT-PCR (Fig. 8). The results showed that these genes were down-regulated in the ospub73 anthers compared with WT during meiosis (Fig. 8h), and the genes expression were similar to our RNA-seq data. At the single microspore stage, the expression levels of CYP703A3, CYP704B2, DPW, PTC1, OsAP37 and OsABCG15 were not greatly changed between WT and ospub73, however, UDT1 was up-regulated in ospub73. At the bi-cellular pollen stage, CYP703A3, CYP704B2 and DPW presented high expression in the ospub73, and expression level of PTC1 and UDT1 was down-regulated in ospub73 (Fig. 8). The ospub73 had such a broad effects on so many important anther development genes, it is plausible to consider it as an important part of the conserved gene regulation network that regulates rice anther development.

\section{Comparison of OsPUB73 regulatory role with those of PTC1, UDT1, GAMYB and TDR (Tapetum Degeneration Retardation) in anther development}

To clarify characterization of OsPUB73, the 2811 DEGs in ospub73 were compared with ptc1 [17], udt1 [13], gamyb-2 [16] and $t d r$ plants [36], and there are $18.27 \%$ (449/2458) DEGs changing in ptc1 mutant, 9.88\% (121/ 1255) DEGs changing in $u d t 1$ plant, $36.78 \%(320 / 870)$ DEGs changing in gamyb-2 plant and $14.72 \%(34 / 231)$ DEGs changing in $t d r$ (Fig. 9). Five genes showed changes of expression in all five mutants (Fig. 9; Additional file 10: Table S5; Additional file 11: Figure S6), including 3-oxoacyl-reductase (LOC_Os12g13930), LTP (lipid transfer protein) family protein (LTPL2, LOC_ Os07g46210), aquaporin protein (LOC_Os01g02190) and male sterility protein (LOC_Os03g07140, DPW) showed down-regulated expression in the all five mutants and pectinesterase (LOC_Os07g41650) showed downregulated expression in ospub73, $u d t 1$, gamyb-2 and $t d r$ plants but up-regulated expression in ptc1 (Additional file 10: Table S5). These genes are involved in lipid metabolism and transport, cell wall, and are played important roles in tapetum and pollen development.

\section{Discussion}

OSPUB73 may play an essential role in male reproductive development

Many previous studies showed that the PUB possesses E3 ubiquitin ligase activity in plant, which has a significant effect on ubiquitination modification, and revealed PUB plays central roles in plant cell death, defense responses, immune reactions and flowering time [28, 29, 32, 33, 37]. In addition, a total of 77 U-box protein genes were found in rice [27]. The SPL11 (OsPUB11) was the first PUB gene to be studied in rice, which harbored E3 ligase activity and involved in the 


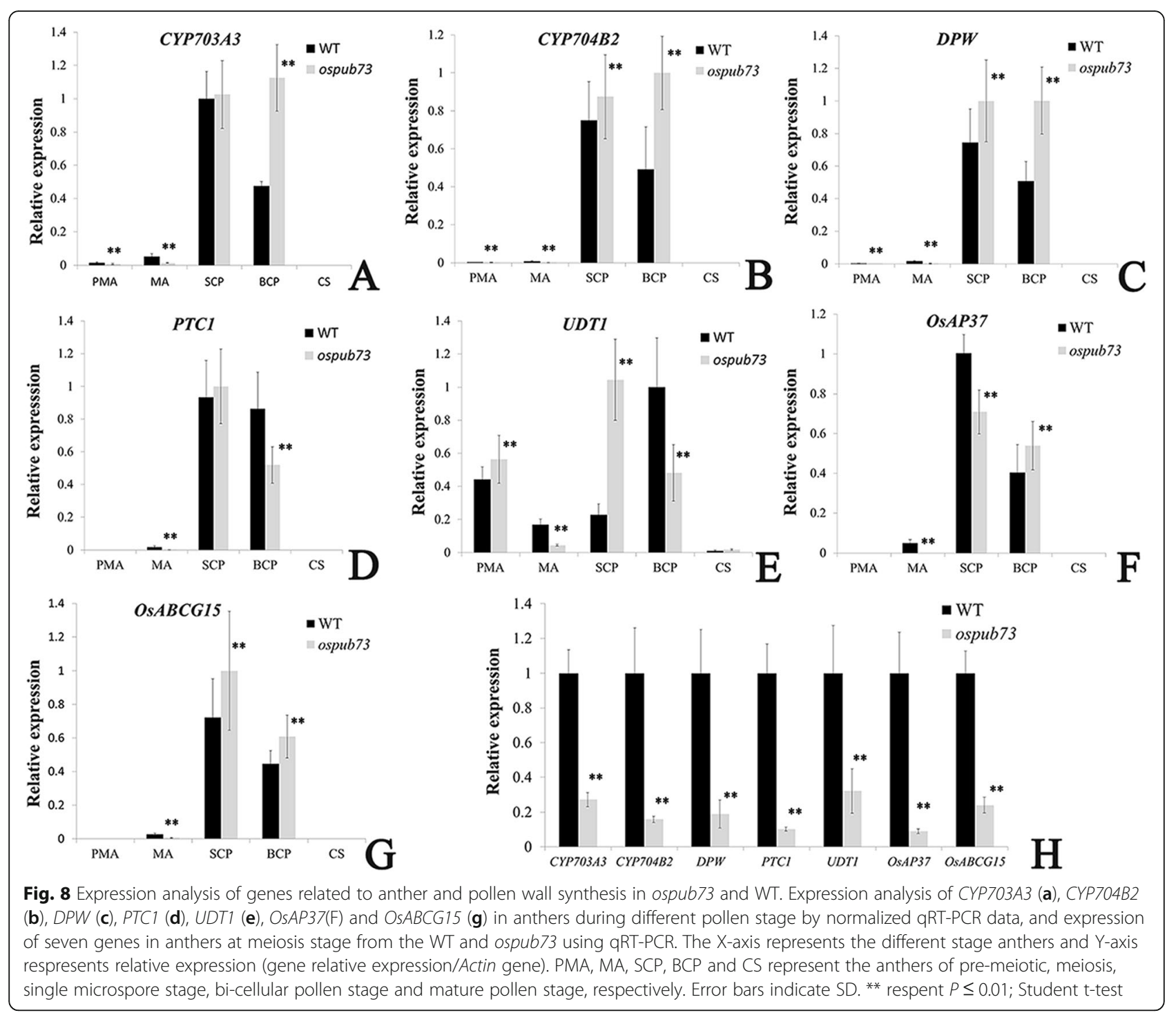

pathway of cell death and defense [38]. Subsequently, the scientists reported OsPUB15 [32], OsPUB44 [39] and OsPUB75 [40]. However, the molecular mechanisms and function PUB genes are still largely unknown. In this study, we identified a PUB gene, OsPUB73, which consists of three exons and two introns. The OsPUB73 possesses E3 ligase activity in vitro [27]. We successfully developed a homozygous ospub73 by CRISPR/Cas9 system. The ospub73 showed normal embryo sac fertility. However, ospub73 showed male semi-sterility.

Meiosis chromosome behavior and anther wall development are essential parts of the correlated plant male reproductive development [41, 42]. The tapetum supplies nutrients and stable environment for microspore development, and the timely degradation of tapetum is crucial for pollen grain formation [4, 43]. The PUB genes were also discovered to have important function in tapetum development and thus affected male reproductive development. Wang et al. [44] reported a PUB gene (AtPUB4) taking part in pollen development in Arabidopsis. The Atpub4 had abnormal expansion of the tapetum layer after the tetrad stage and tapetum layer incomplete degeneration in the end, and absence of AtPUB4 leads to complete male sterility, these results suggested AtPUB4 may be a crucial factor in male sterility. We observed no differences in chromosome behavior between ospub73 and WT by using DAPI staining observation, but the tapetum layer didn't degenerate during mature pollen stage and generated aborted pollen in ospub73. These observations suggested knock-out of OsPUB73 may cause semi-sterility in rice.

OsPUB73 may affect the regulatory network of the genes associated with tapetum or pollen exine development in rice

It is well known that plant male reproductive development is a complex biological process and a large number 


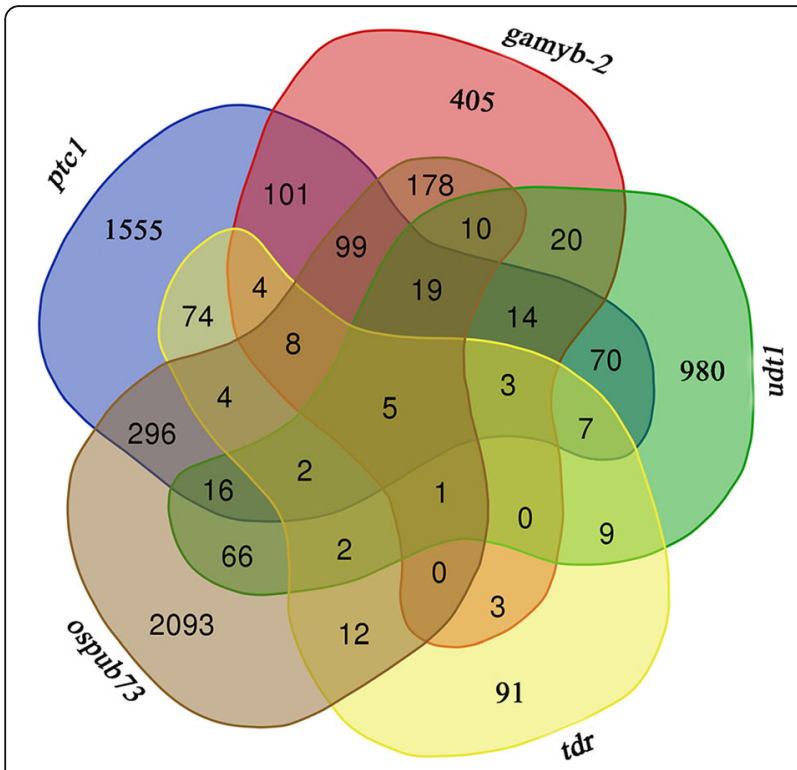

Fig. 9 Comparison of genes expression changed in ospub73, $t d r$, gamyb, udt1 and ptc1 plants

of genes take part in this process [45, 46]. Recently, RNA sequencing (RNA-seq) has been found to be a helpful tool for investigating gene expression and researching gene regulated expression networks [47, 48]. The RNA-seq analysis showed $79.69 \%$ DEGs were down-regulated in the ospub73 compared with WT. This indicated that down-regulated genes may play important roles in male reproduction. Among the down-regulated genes, many DEGs were enriched in the carbohydrate metabolic process, lipid metabolic process and protein modification process, which are related to anther development or pollen wall generation.

Furthermore, we identified seven down-regulated genes in ospub73, which were associated with tapetum development, including CYP703A3, CYP704B2, DPW, PTC1, UDT1, OsAP37 and OsABCG15. UDT1 encodes a helix-loop-helix protein, which is required for tapetal degradation in rice. In the $u d t 1$ mutant, the tapetum becomes vacuolated at the meiosis stage and there is no pollen in anther locules [13]. CYP703A3 and CYP704B2 are cytochrome P450s family genes in rice, which have been specifically detected in the anther and catalyzed hydroxylation of fatty acids. Loss of function of CYP703A3 and $C Y P 704 B 2$ genes caused defective pollen exine and male reproductive development, and the CYP703A3 was directly regulated by $T D R[9,12,49] . D P W$ is a fatty acyl carrier protein reductase and is required for the anther cuticle development and pollen sporopollenin biosynthesis, and the $d p w$ mutant exhibits abnormalities of anther surface and pollen wall and reduction of lipidic Ubisch bodies [10]. OsAP37 is an aspartic protease that is directly regulated by EAT1 (ETERNAL TAPETUM 1) and caused abnormal tapetum in rice [50]. PTC1, which is a PHD-finger protein, controls tapetal PCD in the rice anther development, and absence of PTC1 resulted in changed pollen wall structure and male sterility [17]. OsABCG15 encodes an ATP binding cassette transport protein that plays an important role in pollen exine development by exporting lipids from tapetem to anther locules [51, 52]. The above genes are essential for tapetum or pollen development. The abrupt alteration of the expression patterns of these tapetum-related genes may cause abnormal tapetum and lead to male semisterility in ospub73.

Four transcription factors have been identified to play essential roles in tapetum formation and degeneration in rice, including GAMYB, UDT1, TDR and PTC1. GAMYB is a MYB family transcription factor, $U D T 1$ and TDR encode bHLH family transcription factor, and PTC1 is a PHD-finger transcription factor. The four mutants showed delayed tapetum degeneration and their pollen exine was defective [13, 15-17, 36]. The gamyb, udt1, $t d r$ and ptc1 mutants showed the same phenotype during pollen development, including delayed tapetum degeneration and microspore abortion. In ospub73, we also observed the phenomenon of delayed degradation of tapetum. Furthermore, we found no changes in the expression of OsPUB73 in the gamyb, udt1, $t d r$ and $p t c 1$ plants. In addition, we compared the regulatory networks of OsPUB73, GAMYB, UDT1, TDR and PTC1 [13, $16,17,36]$, and observed that five key genes are coregulated by OSPUB73, GAMYB, UDT1, TDR and PTC1, including $D P W$, LTP precursor (LOC_Os07g46210), aquaporin protein (LOC_OsO1g02190) and pectinesterase (LOC_Os07g41650). Interestingly, these five genes were almost down-regulated in the five mutants except for LOC_Os07g41650 being up-regulated in ptc1. These five genes regulate metabolism and transport of metabolites involved in tapetum or pollen wall development. For example, $D P W$ is a putative fatty acid reductase and plays important roles in pollen wall development [10]. $D P W$ is down-regulated in all five mutants. As reported, LTPs are related to transport lipidic component from tapetum to the microspore in anther, and are crucial for rice pollen wall formation [4, 11]. LOC_Os07g46210 belongs to LTP family in rice, and it is down-regulated in all five mutants. These results showed that these five genes play essential roles in all five mutants and may be important factors in tapetum development.

\section{Conclusions}

In this study, we obtained ospub73 homozygous mutant on a japonica rice variety (Taichung65) by CRISPR/Cas9 system. The ospub73 showed normal vegetative development and mature embryo sac fertility, but exhibited semi-sterility of pollen grain. The cytological observation 
showed that ospub73 tapetum vacuolated during meiosis stage, and pollen exine exhibited abnormal phenomenon at the bi-cellular pollen stage. In addition, some important tapetum-related genes are down-regulated in ospub73 compared with WT. We speculated that the relationships of these genes are not a simple linear regulatory gene network but there is instead a complex gene regulatory network in male reproductive development. This work provides new insights into the role of PUB in rice male reproductive development.

\section{Methods}

\section{Materials}

The japonica cultivar Taichung-65 was used as WT. Taichung-65 plants were planted at the experimental farm of South China Agricultural University (SCAU) under natural conditions.

\section{Development and identification of mutant rice}

OsPUB73 mutants were generated using the CRISPR/ Cas9 system as previously reported [53]. The three target site sequences of OsPUB73 were cloned into the single guide RNA (sgRNA), and the integrated sgRNA expression cassettes of OsPUB73 were incorporated into the CRISPR/Cas9 vector pLYCRISPR/Cas9Pubi-H. Then, the vectors were transferred into Taichung-65. The genomic DNAs of transgenic lines and WT were extracted from young leaves using the CTAB method [54]. The genomic region surrounding the CRISPR target site for OsPUB73 was amplified by PCR, and the segment was subjected to Sanger sequencing to screen for mutants. The $\mathrm{T}_{2}$ plants of homozygous mutant have been used for phenotyping and genetic analysis. The primer sequences used in this study are listed in Additional file 12: Table S6.

\section{Observation of chromosome behavior}

The spikelet was collected from ospub73 and WT with -2 to $2 \mathrm{~cm}$ between their flag leaf cushion and the second to last leaf cushion, and fixed in Carnoy solution (ethanol: acetic acid $=3: 1$ ) over $24 \mathrm{~h}$. Then the samples were stored in $70 \%$ ethanol at $4{ }^{\circ} \mathrm{C}$ after washing two times with $70 \%$ ethanol at $20 \mathrm{~min}$. Anthers were dissected from the floret and placed in a small drop of 1 $\mathrm{mg} / \mathrm{L}$ DAPI on a glass slide. After $5-10 \mathrm{~min}$, the glass slide was covered with a slide cover and was observed under a fluorescence microscope (Leica DMRXA).

\section{Characterization of ospub73 phenotype}

The whole mount eosin B confocal laser scanning microscopy (WE-CLSM) was used to investigate the embryo sac fertility in ospub73 and WT according to Chen et al. [55] with minor modifications. The mature spikelet was collected and fixed in FAA (50\% ethanol: acetic acid: methanol $=89: 6: 5)$. The ovary was removed from the inflorescences, and was rehydrated, stained for eosin B, dehydrated and shifted into a mixed solution (ethanol and methyl salicylate $=1: 1$ ). Finally, the ovary was placed in pure methyl salicylate and examined with a laser scanning confocal microscope (Leica SPE). The pollen fertility of ospub73 and WT were observed according to Chen et al. [35]. For the semi-thin assay, the anthers of ospub73 and WT control plants at different pollen developmental stages were collected and fixed in FAA over $48 \mathrm{~h}$ at room temperature. After dehydration through an ethanol series, tissues were embedded in a Leica 7022 Histeresin Embedding Kit (7022LR) according to the manufacturers' protocol (Heraeus Kulzer). Sections of 2 to $3 \mu \mathrm{m}$ thickness were cut with the microtome (Leica RM2235) and were dried at $60^{\circ} \mathrm{C}$ for $24 \mathrm{~h}$. The sections were stained in $0.5 \%$ toluidine blue $(\mathrm{m} / \mathrm{v})$. The sections were observed and photographed under a microscope (Motic BA200). For the TEM assay, the anthers were collected for fixation, and the process was performed as according to $\mathrm{Li}$ et al. [56].

\section{Real-time quantitative polymerase chain reaction (qRT- $\mathrm{PCR}$ ) assay}

Total RNA was isolated from frozen samples using TRIzol reagent (Invitrogen, USA) according to the manufacturer's instructions. The first-strand cDNA was synthesized using a Prime Script RT reagent Kit with gDNA Eraser (TaKaRa) (Code No.RR047A, TaKaRa) according to the manufacturer's instructions. The qRTPCR reaction was performed on the Roche LightCycler480 by using the TB Green Premix Ex Taq II (Code No.RR820A, TaKaRa), and qRT-PCR reaction process was performed according to Chen et al. [35]. All qRTPCR reactions were performed in three biological replicates. The primers for qRT-PCR are shown in Additional file 12: Table S6.

\section{RNA-seq experiments and data analysis}

The anthers of $\mathrm{T}_{2}$ transgenic lines (homozygous mutant) and WT control plants at the meiotic stage were collected in three biological replicates at $-80{ }^{\circ} \mathrm{C}$ for RNA isolation. Total RNA was taken according to the manual instructions of the TRIzol Reagent (Life technologies, California, USA). The RNA-seq process was performed according to a previously described approach [35]. The gene expression differences between samples were detected using the DESeq package. The DEGs were identified with FDR (false discovery rate) $\leq 0.01$ and the absolute value of $\log 2$ (Fold change) $\geq 1$, and then DEGs were used for subsequent analysis. 


\section{Supplementary information}

Supplementary information accompanies this paper at https://doi.org/10. 1186/s12870-019-2175-2

Additional file 1: Figure S1. Amplification of OSPUB73 CDS.

Additional file 2: Figure S2. Amino acid sequence alignment of OsPUB73 with other $V$ class genes in rice and Arabidopsis.

Additional file 3: Figure S3. The expression pattern analysis of OsPUB73 in Taichung 65

Additional file 4: Table S1. List of the $T_{0}$ result of knockout OsPUB73 by CRISPR/Cas9.

Additional file 5: Figure S4. Plant phenotype of ospub73 and WT plants. (PPTX $399 \mathrm{~kb}$ )

Additional file 6: Table S2. The correlation analysis between all samples. Additional file 7: Figure S5. The principal component analysis (PCA) in WT and mutant plant.

Additional file 8: Table S3. Differentially expressed genes between WT and mutant

Additional file 9: Table S4. Gene ontology (GO) enrichment analysis for differently expressed genes between WT and mutant plant.

Additional file 10: Table S5. Changed expression of genes in ospub73, ptc1, tdr, gamyb-2 and udt1.

Additional file 11: Figure S6. The five important genes expression were confirmed by qRT-PCR in ospub73 and WT.

Additional file 12: Table S6. The primers were used in this study.

\section{Abbreviations}

DAPI: 4,6-diamidino-2-phenylindole; DEGs: Differentially expressed genes; FDR: False discovery rate; GO: Gene ontology; KEGG: Kyoto Encyclopedia of Genes and Genomes; LTP: Lipid transfer protein; PCA: Principal component analysis; PCD: Programmed cell death; PUB: Plant U-box; qRTPCR: Quantitative real-time polymerase chain reaction; RT-PCR: Rverse transcription polymerase chain reaction; TEM: Transmission electron microscopy; WT: Wild type

\section{Acknowledgements}

The authors thank Prof. Guiquan Zhang for donating Taichung 65. We also thank Ms. Shuhong Yu and other lab members for assistance.

\section{Authors' contributions}

$X D L$ and $L C$ conceived and designed the experiments. $L C$ and XDL wrote the paper. LC, RLD, GQL, JJ and JWW performed experiment and analyzed the data. All authors read and approved the final version of the manuscript.

\section{Funding}

This work was supported by the Guangzhou Science and Technology Key Program to XD Liu (201707020015), the NSFC to XD Liu (31571625), the Key Realm R \& D Program of Guangdong Province (2018B020202012) and the Opening Foundation of Guangdong Province Key Laboratory of Plant Molecular Breeding (GPKLPMB201803). The funders had no role in the design of the study and collection, analysis, and interpretation of data and in writing the manuscript.

\section{Availability of data and materials}

The RNA-seq data are available from the NCBI under the accession number PRJNA578476

All data supporting the conclusions described here are provided in tables, figures, and additional files.

\section{Ethics approval and consent to participate}

Not applicable

\section{Consent for publication}

Not applicable

\section{Competing interests}

The authors declare that they have no competing interests.

\section{Author details}

${ }^{1}$ State Key Laboratory for Conservation and Utilization of Subtropical Agro-Bioresources, South China Agricultural University, Guangzhou 510642, China. ${ }^{2}$ Guangdong Provincial Key Laboratory of Plant Molecular Breeding, South China Agricultural University, Guangzhou 510642, China. ${ }^{3}$ Guangdong Laboratory for Lingnan Modern Agriculture, South China Agricultural University, Guangzhou 510642, China. ${ }^{4}$ Vegetable Research Institute, Guangdong Academy of Agricultural Sciences, Guangzhou 510640, China. ${ }^{5}$ Guangdong Key Laboratory for New Technology Research of Vegetables, Guangzhou 510640, China.

Received: 12 September 2019 Accepted: 29 November 2019

Published online: 10 December 2019

\section{References}

1. Gomez JF, Talle B, Wilson ZA. Anther and pollen development: a conserved developmental pathway. J Integr Plant Biol. 2015;57(11):876-91.

2. Itoh J, Nonomura K, Ikeda K, Yamaki S, Inukai Y, Yamagishi H, Kitano H, Nagato Y. Rice plant development: from zygote to spikelet. Plant Cell Physiol. 2005;46(1):23-47

3. Ariizumi T, Toriyama K. Genetic regulation of sporopollenin synthesis and pollen exine development. Annu Rev Plant Biol. 2011;62:437-60.

4. $\quad$ Li N, Zhang D, Liu H, Yin C, Li X, Liang W, Yuan Z, Xu B, Chu H, Wang J, et al. The rice tapetum degeneration retardation gene is required for tapetum degradation and anther development. Plant Cell. 2006;18(11):2999-3014.

5. Wu HM, Cheun AY. Programmed cell death in plant reproduction. Plant Mol Biol. 2000;44(3):267-81.

6. Papini A, Mosti S, Brighigna L. Programmed-cell-death events during tapetum development of angiosperms. Protoplasma. 1999;207(3-4):213-21.

7. Li L, Li Y, Song S, Deng H, Li N, Fu X, Chen G, Yuan L. An anther development F-box (ADF) protein regulated by tapetum degeneration retardation (TDR) controls rice anther development. Planta. 2015:241(1):157-66.

8. Cao H, Li X, Wang Z, Ding M, Sun Y, Dong F, Chen F, Liu L, Doughty J, Li Y, et al. Histone $\mathrm{H} 2 \mathrm{~B}$ monoubiquitination mediated by HISTONE MONOUBIQUITINATION1 and HISTONE MONOUBIQUITINATION2 is involved in anther development by regulating tapetum degradation-related genes in rice. Plant Physiol. 2015;168(4):1389-514

9. Yang X, Wu D, Shi J, He Y, Pinot F, Grausem B, Yin C, Zhu L, Chen M, Luo Z, et al. Rice CYP703A3, a cytochrome P450 hydroxylase, is essential for development of anther cuticle and pollen exine. J Integr Plant Biol. 2014;56(10):979-94.

10. Shi J, Tan H, Yu XH, Liu Y, Liang W, Ranathunge K, Franke RB, Schreiber L, Wang $Y$, Kai $G$, et al. Defective pollen wall is required for anther and microspore development in rice and encodes a fatty acyl carrier protein reductase. Plant Cell. 2011;23(6):2225-46.

11. Zhang D, Liang W, Yin C, Zong J, Gu F, Zhang D. OsC6, encoding a lipid transfer protein, is required for postmeiotic anther development in rice. Plant Physiol. 2010;154(1):149-62.

12. Morant M, Jorgensen $K$, Schaller H, Pinot F, Moller BL, Werck-Reichhart D, Bak S. CYP703 is an ancient cytochrome P450 in land plants catalyzing inchain hydroxylation of lauric acid to provide building blocks for sporopollenin synthesis in pollen. Plant Cell. 2007;19(5):1473-87.

13. Jung KH, Han MJ, Lee YS, Kim YW, Hwang I, Kim MJ, Kim YK, Nahm BH, An G. Rice undeveloped Tapetum1 is a major regulator of early tapetum development. Plant Cell. 2005;17(10):2705-22.

14. Yang Z, Liu L, Sun L, Yu P, Zhang P, Abbas A, Xiang X, Wu W, Zhang Y, Cao $L$, et al. OsMS1 functions as a transcriptional activator to regulate programmed tapetum development and pollen exine formation in rice. Plant Mol Biol. 2019;99(1-2):175-91.

15. Liu Z, Bao W, Liang W, Yin J, Zhang D. Identification of gamyb-4 and analysis of the regulatory role of GAMYB in rice anther development. J Integr Plant Biol. 2010;52(7):670-8.

16. Aya K, Ueguchi-Tanaka M, Kondo M, Hamada K, Yano K, Nishimura M, Matsuoka M. Gibberellin modulates anther development in rice via the transcriptional regulation of GAMYB. Plant Cell. 2009;21(5):1453-72.

17. Li H, Yuan Z, Vizcay-Barrena G, Yang C, Liang W, Zong J, Wilson ZA, Zhang D. PERSISTENT TAPETAL CELL1 encodes a PHD-finger protein that is required for tapetal cell death and pollen development in rice. Plant Physiol. 2011; 156(2):615-30 
18. Ciechanover A. Intracellular protein degradation: from a vague idea thru the lysosome and the ubiquitin-proteasome system and onto human diseases and drug targeting. Cell Death Differ. 2005;12(9):1178-90.

19. Sullivan JA, Shirasu K, Deng XW. The diverse roles of ubiquitin and the 265 proteasome in the life of plants. Nat Rev Genet. 2003;4(12):948-58.

20. Ciechanover A, Schwartz AL. The ubiquitin-proteasome pathway: the complexity and myriad functions of proteins death. Proc Natl Acad Sci U S A. 1998;95(6):2727-30

21. Jung C, Zhao P, Seo JS, Mitsuda N, Deng S, Chua N. PLANT U-BOX PROTEIN10 regulates MYC2 stability in Arabidopsis. Plant Cell. 2015;27(7): 2016-31.

22. Vierstra RD. The ubiquitin-26S proteasome system at the nexus of plant biology. Nat Rev Mol Cell Biol. 2009;10(6):385-97.

23. Moon J, Parry G, Estelle M. The ubiquitin-proteasome pathway and plant development. Plant Cell. 2004;16(12):3181-95.

24. Ciechanover A. The ubiquitin-proteasome pathway: on protein death and cell life. EMBO J. 1998;17(24):7151-60.

25. Ohi MD, Vander KC, Rosenberg JA, Chazin WJ, Gould KL. Structural insights into the U-box, a domain associated with multi-ubiquitination. Nat Struct Biol. 2003;10(4):250-5.

26. Koegl M, Hoppe T, Schlenker S, Ulrich HD, Mayer TU, Jentsch S. A novel ubiquitination factor, E4, is involved in multiubiquitin chain assembly. Cell. 1999;96(5):635-44.

27. Zeng LR, Park CH, Venu RC, Gough J, Wang GL. Classification, expression pattern, and E3 ligase activity assay of rice U-box-containing proteins. Mol Plant. 2008;1(5):800-15.

28. Liu YC, Wu YR, Huang XH, Sun J, Xie Q. AtPUB19, a U-box E3 ubiquitin ligase, negatively regulates abscisic acid and drought responses in Arabidopsis thaliana. Mol Plant. 2011:4(6):938-46.

29. Seo DH, Ryu MY, Jammes F, Hwang JH, Turek M, Kang BG, Kwak JM, Kim WT. Roles of four Arabidopsis U-box E3 ubiquitin ligases in negative regulation of abscisic acid-mediated drought stress responses. Plant Physiol. 2012;160(1):556-68.

30. Park JJ, Yi J, Yoon J, Cho LH, Ping J, Jeong HJ, Cho SK, Kim WT, An G. OsPUB15, an E3 ubiquitin ligase, functions to reduce cellular oxidative stress during seedling establishment. Plant J. 2011;65(2):194-205.

31. Li W, Ahn IP, Ning Y, Park CH, Zeng L, Whitehill JG, Lu H, Zhao Q, Ding B, Xie Q, et al. The U-box/ARM E3 ligase PUB13 regulates cell death, defense, and flowering time in Arabidopsis. Plant Physiol. 2012;159(1):239-50.

32. Wang J, Qu B, Dou S, Li L, Yin D, Pang Z, Zhou Z, Tian M, Liu G, Xie Q, et al. The E3 ligase OsPUB15 interacts with the receptor-like kinase PID2 and regulates plant cell death and innate immunity. BMC Plant Biol. 2015;15:49.

33. Yang CW, Gonzalez-Lamothe R, Ewan RA, Rowland O, Yoshioka H, Shenton M, Ye H, O'Donnell E, Jones JD, Sadanandom A. The E3 ubiquitin ligase activity of arabidopsis PLANT U-BOX 17 and its functional tobacco homolog ACRE276 are required for cell death and defense. Plant Cell. 2006;18(4): 1084-98.

34. Wu J, Shahid MQ, Chen L, Chen Z, Wang L, Liu X, Lu Y. Polyploidy enhances $F_{1}$ pollen sterility loci interactions that increase meiosis abnormalities and pollen sterility in autotetraploid rice. Plant Physiol. 2015;169(4):2700-17.

35. Chen L, Shahid MQ, Wu J, Chen Z, Wang L, Liu X. Cytological and transcriptome analyses reveal abrupt gene expression for meiosis and saccharide metabolisms that associated with pollen abortion in autotetraploid rice. Mol Gen Genomics. 2018;293(6):1407-20.

36. Zhang DS, Liang WQ, Yuan Z, Li N, Shi J, Wang J, Liu YM, Yu WJ, Zhang DB. Tapetum degeneration retardation is critical for aliphatic metabolism and gene regulation during rice pollen development. Mol Plant. 2008;1(4):599-610.

37. Wang N, Xing Y, Lou Q, Feng P, Liu S, Zhu M, Yin W, Fang S, Lin Y, Zhang T, et al. Dwarf and short grain 1, encoding a putative U-box protein regulates cell division and elongation in rice. J Plant Physiol. 2017;209:84-94.

38. Liu J, Park CH, He F, Nagano M, Wang M, Bellizzi M, Zhang K, Zeng X, Liu W, Ning $Y$, et al. The RhoGAP SPIN6 associates with SPL11 and OsRacl and negatively regulates programmed cell death and innate immunity in rice. PLoS Pathog. 2015;11(2):e1004629.

39. Ishikawa K, Yamaguchi K, Sakamoto K, Yoshimura S, Inoue K, Tsuge S, Kojima C, Kawasaki T. Bacterial effector modulation of host E3 ligase activity suppresses PAMP-triggered immunity in rice. Nat Commun. 2014;5:5430.

40. Hu X, Qian Q, Xu T, Zhang Y, Dong G, Gao T, Xie Q, Xue Y. The U-box E3 ubiquitin ligase TUD1 functions with a heterotrimeric $G$ alpha subunit to regulate Brassinosteroid-mediated growth in rice. PLoS Genet. 2013;9(3): e1003391.
41. Goldberg R, Beals T, Sanders P. Anther development: basic principles and practical applications. Plant Cell. 1993;5(10):1217-29.

42. Luo Q, Li Y, Shen Y, Cheng Z. Ten years of gene discovery for meiotic event control in rice. J Genet Genomics. 2014;41(3):125-37.

43. Xu J, Yang C, Yuan Z, Zhang D, Gondwe MY, Ding Z, Liang W, Zhang D, Wilson ZA. The ABORTED MICROSPORES regulatory network is required for postmeiotic male reproductive development in Arabidopsis thaliana. Plant Cell. 2010;22(1):91-107.

44. Wang H, Lu Y, Jiang T, Berg H, Li C, Xia Y. The Arabidopsis U-box/ARM repeat E3 ligase AtPUB4 influences growth and degeneration of tapetal cells, and its mutation leads to conditional male sterility. Plant J. 2013;74(3): 511-23.

45. Fujita M, Horiuchi $Y$, Ueda Y, Mizuta Y, Kubo T, Yano K, Yamaki S, Tsuda K, Nagata T, Niihama $M$, et al. Rice expression atlas in reproductive development. Plant Cell Physiol. 2010;51(12):2060-81.

46. Suwabe K, Suzuki G, Takahashi H, Shiono K, Endo M, Yano K, Fujita M, Masuko H, Saito H, Fujioka T, et al. Separated transcriptomes of male gametophyte and tapetum in rice: validity of a laser microdissection (LM) microarray. Plant Cell Physiol. 2008;49(10):1407-16.

47. Sun W, Hui XX, Lu X, Xie L, Bai B, Zheng C, Sun H, He Y, Xie XZ. The rice phytochrome genes, PHYA and PHYB, have synergistic effects on anther development and pollen viability. Sci Rep. 2017:7(1):6439.

48. Lin H, Yu J, Pearce SP, Zhang D, Wilson ZA. RiceAntherNet: a gene coexpression network for identifying anther and pollen development genes. Plant J. 2017;92(6):1076-91.

49. Li H, Pinot F, Sauveplane V, Werck-Reichhart D, Diehl P, Schreiber L, Franke R, Zhang P, Chen L, Gao Y, et al. Cytochrome P450 family member CYP704B2 catalyzes the \{omega\}-hydroxylation of fatty acids and is required for anther cutin biosynthesis and pollen exine formation in rice. Plant Cell. 2010;22(1):173-90.

50. Niu N, Liang W, Yang $X$, Jin W, Wilson ZA, Hu J, Zhang D. EAT1 promotes tapetal cell death by regulating aspartic proteases during male reproductive development in rice. Nat Commun. 2013:4(1445):1.

51. Zhao G, Shi J, Liang W, Xue F, Luo Q, Zhu L, Qu G, Chen M, Schreiber L, Zhang D. Two ATP binding cassette $G$ transporters, rice ATP binding cassette G26 and ATP binding cassette G15, collaboratively regulate rice male peproduction. Plant Physiol. 2015;169(3):2064-79.

52. Wu L, Guan Y, Wu Z, Yang K, Lv J, Converse R, Huang Y, Mao J, Zhao Y, Wang $Z$, et al. OsABCG15 encodes a membrane protein that plays an important role in anther cuticle and pollen exine formation in rice. Plant Cell Rep. 2014;33(11):1881-99.

53. Ma X, Zhang Q, Zhu Q, Liu W, Chen Y, Qiu R, Wang B, Yang Z, Li H, Lin Y, et al. A robust CRISPR/Cas9 system for convenient, high-efficiency multiplex genome editing in monocot and dicot plants. Mol Plant. 2015;8(8):1274-84.

54. Cota-Sanchez JH, Remarchuk K, Ubayasena K. Ready-to-use DNA extracted with a CTAB method adapted for herbarium specimens and mucilaginous plant tissue. Plant Mol Biol Report. 2006;24:161-7.

55. Chen L, Yuan Y, Wu J, Chen Z, Wang L, Shahid MQ, Liu X. Carbohydrate metabolism and fertility related genes high expression levels promote heterosis in autotetraploid rice harboring double neutral genes. Rice. 2019; 12(1):34.

56. Li X, Gao X, Wei Y, Deng L, Ouyang Y, Chen G, Li X, Zhang Q, Wu C. Rice APOPTOSIS INHIBITOR5 coupled with two DEAD-box adenosine 5'triphosphate-dependent RNA helicases regulates tapetum degeneration. Plant Cell. 2011:23(4):1416-34.

\section{Publisher's Note}

Springer Nature remains neutral with regard to jurisdictional claims in published maps and institutional affiliations. 